\title{
Children in Institutions
}

\author{
I. KOLVIN
}

Over the last decade, seriously substandard conditions of physical, psychological and social service care have been reported of children living in institutions. It has not been difficult for the media to highlight the consequences of such incarceration of children in Romania and also on the Greek island of Leros. In some cases, such institutionalisation had been regarded as a necessary provision: for some homeless, difficult children it comprised a more humane upbringing than they would otherwise have received; in other cases, children were thought to need institutional care and management because of physical and/or mental handicap, and/or disturbed behaviour. However, when such programmes go wrong, they go seriously wrong. Those who visit such institutions are often struck by the poor quality of care and relative absence of clinical skills and educational resources, compounded by paucity of ideas about how to stimulate children and the crucial importance of links with the family. In addition, such programmes are often starved of funding and other resources. Further, secondary deprivation is often superimposed, irrespective of the basis of the primary clinical condition. The administrators of such institutions often appear oblivious to the development of new models of care geared to deinstitutionalisation and community rehabilitation, and the provision of appropriate opportunities for education and vocational training of the residents leading, it is hoped, to the possibility of some integration in society.

\section{Whistle blowing}

The judgements of those who visit will depend on their background: journalists subsequently may describe the circumstances as incarceration and dehumanisation, rather than focusing on parenting and stimulation; health care professionals may identify all those qualities of institutionalisation so vividly described by King et al (1971) in their classic book; epidemiologists will seek evidence of the nature and severity of the effects of serious deprivation (Kolvin et al, 1990). But the reality of the situation in the Children's Institution at PIKPA, Leros was so gross that it almost defied belief.

\section{The Leros 'Children's' Institution}

The Children's Care Institution (CCI) on the island of Leros was established in 1962. It is attached to PIKPA, Greece's largest child welfare organisation. In 1991 it catered for 167 "children" some of whom had been admitted and retained there or remained there for about 30 years, the oldest now being about 45 years, and only about one in five under the age of 18.

The history and geographical situation of Leros is important. It is an island in the Dodecanese, close to the Turkish coast, giving it a strategic significance. This isolation has led to its role, which has been described in the official documents and in the international press as a "dumping ground for the unwanted and outcasts, for lepers, for convicts, for political prisoners and the mentally ill". The horrific conditions of the mental health services on Leros have been documented in newspaper articles. A report in the Observer (1986) described both the results of such incarceration-patients with no dignity; a lack of care; a lack of clinical skills of staff; a lack of psychosocial leadership - and the processes by which these circumstances are perpetuated - the lack of funding for a reform programme, either from the Greek government or the EU, and local political issues, arising from the fact that the island's economy was so heavily dependent on the patient population.

Two other factors were important: these were, first, that the Greek mental health professionals campaigning for change had, in the past, been subject to acrimony and intimidation; second, the view that involvement with Leros was likely to blight future career prospects. However, the international exposure of the circumstances in the Leros Institution eventually promoted change by influencing public opinion and encouraging EEC support of intervention programmes.

In 1991, Professor John Tsiantis of Athens University courageously took up the challenge by mounting a pilot reform programme for the 'Children's Hospital' of Leros. He gathered together an impressive multidisciplinary team of psychiatrists, psychologists, teachers, social workers, occupational therapists, physiotherapists, nurses and a neurologist. An important and remarkable 
phenomenon was the willingness of young skilled professionals to go to work in such deprived settings with such major problems. Professor Tsiantis also availed himself of help, skills and expertise of visiting experts such as Professor A. Gath (University College), Professor I. Kolvin (Tavistock and Royal Free), Dr T. Fundudis (Nuffield Unit, Newcastle) and Mrs V. Sinason (Tavistock) of the UK; and Dr L. Lier (Copenhagen).

\section{Circumstances within the 'Children's' Institution}

On the basis of personal observations and from available documentation the following were the circumstances within the institution at the beginning of the project:

The patients lived in old military-type accommodation, constructed in 1930 , consisting of a large two-storey building, with accommodation on both floors. It was a grim, rather neglected-looking building, unsuitable for the needs of the inhabitants. For the most part, the ambulant inhabitants lived on the lower floor and the immobile patients on the upper floor; as there were no lifts or ramps, there was little possibility of the patients on the upper floor being able to enjoy any walks or tours of the grounds in their wheelchairs. Many of these patients had lived their whole lives in a bed on the upper floor. It was only over the previous two years that toilets and bathrooms had been built at the end of the wards. In theory, there were too few of these; in practice, they were little used, as patients had not been instructed or trained to use them. Because of those circumstances, very few patients used the toilets and mainly they urinated and defecated on the floor. The patients lived in communicating 16 bed wards, separated by huge doors; the overall impression was of enormous rooms with high ceilings, devoid of a sense of home or comfort.

Many of the older patients roamed around in various forms of undress or even nudity. As to management and care, there was little to encourage individualisation, with every form of management or care being identical. Thus, there was a sense of uniformity about the whole process of care, with little in the way of attempts to personalise care, and with the patients being dealt with in lines or groups or queues or by other patients, but not as individuals; there were few specialised activities; there were hardly any toys for the younger patients; there were no personal belongings. In the upstairs wards, many of the patients were immobilised in their beds, and there was little evidence of attempts to help to develop motor function: inevitably, some of these patients had developed quite serious disuse contractures. For various reasons, some patients were restrained to their beds with straps. There was an absence of any materials relating to education, occupational therapy or physiotherapy. The care and management was of an old-fashioned authoritarian type, but even that to a low standard. The care was often primitive, with the more able residents contributing substantially to the care of the less fortunate ones. However, observers had noted a number of individual acts of kindness by the staff to the patients. Nevertheless, the staff were no more than custodians, with minimal nursing and caring skills and with rigid attitudes to management.

Less than one in ten residents had received a visit from their family over a period of a year. Tsiantis et al point out that in Greece the social stigma of mental handicap of a family member affects the status of the entire family, and perhaps, facilitates the concealment of the affected family member.

The medical care too, was of a primitive nature. The physical diagnoses were usually inadequate and out of date and there were few psychiatric diagnoses. There had been no regular re-assessments. Often, forms of drug therapy had apparently not changed over the years. The clinical diagnoses were fivefold first, medical, second, physical handicap; third, mental handicap; fourth, mental disorder (often inadequately specified); and fifth, the secondary severe effects of longstanding institutionalisation and deprivation.

The only trained staff were a matron and an administrative director. The rest of the staff numbered 120 , of which $38 \%$ were works staff and 'technical' staff. The other nursing and care staff were untrained and most had only had primary school education. There were little in the way of inservice or out-service training programmes and no systematic organisation or structure of the care or nursing staff.

\section{The reform, intervention and rehabilitation programme}

In the face of the above, Professor Tsiantis, with assistance of EEC funding and in collaboration with a non-governmental organisation (the Association for the Psychological Health of Children and Adolescents), mounted a 4-year pilot programme with two subgroups of residents: younger with severe disabilities and older with less severe disabilities. The aim of the programme was to set up two multidisciplinary teams whose tasks would be manifold. Initially, they would record the shortcomings of the institution, of physical and 
general care. Second, a staff training programme would be initiated - the teams would negotiate with staff in the institution to introduce new models of care and management. Third, they would launch an intervention programme in the wards, geared to upgrade or improve medical and social care and reduce the institutionalisation experiences. Fourth, they would establish a rehabilitation programme. Fifth, they would seek to improve the overall social environment and to improve the links between the institution and the community. Sixth, their aim would be to develop projects to provide care and education of the residents, helping them to improve their living and social skills and behaviour. Seventh, to develop a hostel for six residents in the grounds of the institution. Finally, to reorganise the wards, modelling them on care units.

In the supplement to this journal the project team honestly outline their endeavours and their many achievements, but they also describe their disappointments and frustrations. All will applaud them. They emphasise the fundamental importance of staff training and the essential need to identify ways of changing attitudes. It is a monumental effort that provides compelling reading for those in the field and beyond.

The intervention team acted as teachers, trainers, demonstrators and catalysts of change rather than becoming members of the staff. What were the results? Some of the changes were immediate and dramatic. One 16-year-old youth had been tied to his bed for most of his life because of epileptic fits and there was consequently disuse atrophy of the restrained limb - when restraint was removed he learned to walk within a month; quite soon one resident had been rehabilitated back to his home; with improved relations with the local community, two residents have been permanently fostered on the island. Obviously, wider rehabilitation has been given priority. Rehabilitation included the setting up of a community home in Athens to which 11 residents from PIKPA were transferred where they were provided with more opportunities for more normal living and improved care. $\mathbf{A}$ more rational programme of medical care and prescribing of medicines has been established at PIKPA. However, those achievements, with relation to physical conditions and improved facilities for hygiene, have taken some time to establish - so too has an improved physiotherapy programme. The buildings have now been renovated and are operating under much improved physical and hygienic conditions. There is now an elevator and also ramps leading to the courtyard.

Staff management procedures have also changed, but this was only after substantial input from the project team. This change was effected despite the resistance met by the project team both from the administration and the local community on the Leros island. The new administration last year appointed over 50 new members of staff among which are 15 trained nurses, physiotherapists, and special teachers. In 1995 a training programme for new and old staff has been established.

The care staff, despite all the training received and input, maintained substantially negative attitudes towards subjects with learning disabilities, although there were some demonstrable changes. The researchers argue that the resistance to change was due to an interplay of cultural, attitudinal, psychodynamic and socio-economic factors.

\section{Wider implications}

Institutions, such as Leros PIKPA, constitute the extreme end of the spectrum of care, where people are identified as different, perhaps scapegoated and moved out of sight. Leros highlights the problems that can result from the well-meaning policy of the self-contained community, which can be thought of as functioning effectively, but which, without external input, can gravitate into neglect and deprivation.

A crucial question is whether the above phenomena are representative only of less affluent societies? While unacceptable standards are less widespread in the more affluent societies, it is disconcerting to find that, even in these, there are often crises of care in official settings. Lesser degrees of such extremes are not unknown even in the AngloAmerican scene. Examples of such crises in the UK relate to misconceptions of ideology; these include school and homes for 'unusual' children who may be exposed to unacceptable programmes of care or abuse, especially where there is no external monitoring; some misunderstandings of the principles of behaviour modification of disturbed children; and the occasional over-reliance on the use of tranquillisers rather than on psychotherapeutic skills. These circumstances clearly contravene prevailing opinions about reasonable standards and the perceived needs of special children.

\section{Rehabilitation and prevention}

Rehabilitation and rehabilitation back into the community were pivotal in Tsiantis's programme. However, it should be remembered that it is only in the last two decades that there have been serious efforts to keep people with learning disabilities in the 
community. Unfortunately, some institutions, and even some countries, have been left behind: hence, in each country (including the UK), policy and philosophy regarding the development and organisation of programmes of care and protection of vulnerable, disabled and 'special' children needs to be established, with adequate daytime education, occupation or recreation. Intellectually or psychologically handicapped children are high risk groups. Traditionally, learning disabilities were thought to preclude dynamic therapy, but this ideological denial of therapy is clearly out of date. Rather, treatment of children requires special communication skills and awareness, or at least supervision in the application of these skills (Sinason, 1992). To this end, several principles have been formulated which, if adhered to, will reduce the likelihood of local or national crises.

In brief, inevitably many of the solutions are political (Ryan \& Thomas, 1987). Thus there should be state or governmental guidelines concerning good practice. Institutions should publicly declare their principles of policy and philosophy of care and therapeutic management for both existing and new programmes; they should ensure that all are aware of the nature of such programmes and their educational, social and psychotherapeutic content; and the central role of the philosophy of normalisation. They should seek understanding and support from both public and professionals; and, importantly, from relatives, as change in AngloAmerican care has often largely come about as a result of pressure from relatives (Berney $T$. $P$. - personal communication). Such programmes require an appropriately coordinated multidisciplinary and multi-agency input, with adequately trained staff and reasonable budgets. Further interagency cooperation in the care and protection of vulnerable and handicapped people is essential.

Finally, to determine the efficacy of the various programmes it is essential that the work of such institutions should be periodically reviewed, with both internal audit and external assessments. For the latter purposes a major safeguard would be the appointment of assessors who are experts in both the relevant and allied fields, but who are independent of, and external to, the programme in question, to ensure that any reform and developing practices have national and international sanction. It is hoped that such principles will lead to an improvement in the conditions of care and protection of extremely vulnerable children, irrespective of the affluence of the society.

\section{Conclusion}

There are three major conclusions. First, identification of future leaders and teachers in all relevant professions must be a priority as it is only these local experts who can bring about more permanent change (Gath, 1992). Second, the lessons learnt and the skills developed by Professor Tsiantis's team should prove an invaluable resource to other institutions in Greece and in other countries, and it would be a shame to allow the Athens team to fragment and the skills to be lost. Finally, the importance of whistle-blowing, as one of the catalysts of change, should not be underestimated.

\section{Acknowledgements}

I am indebted to Dr T. P. Berney, Mrs V. Sinason and Dr T. Fundudis all of whom offered comments on an earlier draft.

\section{References}

GATH, A. (1992) A visit to Romania in October 1990 and Leros in May 1991. Journal of Intellectual Disability Research, 36, 3-5.

King, D. R., Raynes, V. N. \& Tizard, J. (1971) Patterns of Residential Care. Sociological studies in Institutions for Handicapped Children. London: Routledge \& Kegan Paul.

Kolvin, I. Miller, F. J. W. SCott, D. McI, et al (1990) Continuities of Deprivation. Avebury, Aldershot: ESRC DHSS.

Ryan, J. \& Thomas, D. F. (1987) The Politics of Mental Handicap. London: Free Association Books.

SinAson, V. (1992) Mental Handicap and the Human Condition. London: Free Association Books.

Professor I. Kolvin, The Royal Free Hospital School of Medicine and The Tavistock Clinic, 120 Belsize Lane, London NW3 5BA 